\title{
CRIANÇA COM DOENÇA TERMINAL: REAÇŌES DA FAMÍLIA, ASSISTÊNCIA PRESTADA E DIFICULDADES SENTIDAS PELO ENFERMEIRO DE UNIDADE PEDIÁTRICA. SĀO PAULO, 1987
}

\author{
Ana Luicia de Moraes Horta* \\ Ana Paula de Campos Araújo*** \\ Carla Metello Aprile** \\ Constanza Machado Echalar** \\ Fatima Neves Paredes* \\ Sirlene Caminada**
}

HORTA, A. L. DE N.; ARAÚJO, A. P. C.; APRILE, C. M.; ECHALAR, C. M.; PAREDES, F. N.; CAMINADA, S. Criança com doença terminal: reaçōes da famnlia, assistência prestada e dificuldades sentidas pelo enfermeiro de unidade pediátrica, São Paulo, 1987. Rev. Esc. Enf. USP, São Paulo, 23(2): - , ago. 1989.

$O$ trabalho é um estudo sobre as reaçōes da famnia frente a criança com doença terminal identificadas pelos enfermeiros. Enfoca a assistência proposta a esta famnia e dificuldades sentidas por estes profissionais frente a morte iminente.

$O$ estudo foi realizado com 35 enfermeiros de dois hospitais de ensino, Säo Paulo, 1987. Para o tratamento dos dados foram utilizados os estagios do morrer de KUBLER-ROSS ${ }^{5}$ e o guia de comunicação com os pais de WHALEY WONG ${ }^{9}$.

UNITERMOS: Enfermagem pediatrica. Assistência de enfermagem. Cuidados finais.

\section{INTRODUÇĀO}

Observa-se em Unidades pediátricas que os profissionais de saúde apresentam dificuldades com a assistência direta à criança com doença terminal, bem como com a sua família já que esta também necessita de cuidados.

Segundo WILLLANS et alii 8 muitas enfermeiras fogem e se afastam da família de uma criança com doença terminal. Talvez isso ocorra porque desconhecem o que acontece com esta famulia.

\footnotetext{
** Alunas do 4 ano do Curso de Gaduaçăo da Escola de Enfermagem da Universidade de São Paulo

* Enfermeira. Aluna do Programa de Pós-Graduação em Enfermagem, nivel mestrado da Escola ue Enfermagem da Universidade de Såo Paulo.
} 
Alén disso, supōe-se que exista uma incapacidade desses profissionais em lidar com o tema morte e morrer. Pode-se pensar que isso se dê pela forma como o assumto é abordado durante o curso de graduacão, já que não há uma continuidade e aprofundamento sobre o tema. De acondo com KUBLER-ROSS 5 , já na infância scmos afastados das pessoas que estīo morrendo ou já momeram ou mesmo de assuntos ligados a morte. Dessa forma no decorrer de nossas vidas passamos a usar mecanismos de defesa para lidar com a dor $e$ a ansiedade que essa perda traz.

Outro fator relevante, diz respeito a formaçāo do profissional de saúde voltada para a área curativa. Sendo assim, a morte de um paciente é sentida como um fracasso, trazendo uma carga de angústia e estresse, fazendo com que o profissional se afaste ainda mais dessa situaçâo.

GAUDERER $^{3}$ afirma que o medo da morte e da terminalidade leva o profissional de saúde a se preccupar mais com problemas somáticos e com o prognóstico, por ser mais facil e concreto de se lidar, do que com os problemas emocionais, como por exemplo lidar com as reaçōes, ansiedade, medo, culpa e fases que a familia passa frente a morte iminente. Isto implicaria em que o profissional teria que analisar seus proprios medos, inseguranças, receios e outros sentimentos que podem ser frequentemente desagradáveis.

Porem, segundo BOEMER ${ }^{1}$, as familias de pacientes em fase final necessitam discutir seus sentimentos sobre morte e o enfermeiro precisa estar preparado para manejar esses sentimentos e discutir altemativas, lembrando que a morte afeta as pessoas de maneiras diferentes. Além disso percebe-se que as "famílias terminais", experimentam uma involução intensa e transformadora do ponto de vista de sua estrutura psicodinâmica. A morte de um dos membros desta familia representa tambem a morte simbolica dessa estrutura, e cabe aos sobreviventes reconstruir um sistema familiar que garanta sua viabilidade no futuro.

Por todos os motivos apresentados e pelos sentimentos de impotência e insegurança sentidos por nós frente a familia de uma criança com doença terminal, sentimos a necessidade de conhecer como o enfermeiro de unidade pediátrica identifica as reações da "família terminal", como a está assistindo e quais as dificuldades por ele sentidas nesta assistência.

Definição de termos:

FAMILIA: pessoas responsáveis pela criança com a qual os enfermeiros entram em contato durante a assistência.

\section{METODOLOGIA}

O estudo foi realizado com enfermeiros de Unidade Pediátrica em hospitais de ensino de caráter govemamental da cidade de São Paulo, 1987. 
Sendo a populaçāo de 46 enfermeiros que receberam os questionários, obtivemos uma amostra de 35 questionários que representa $76,00 \%$ da população.

$O$ instrumento para coleta de dados consistiu num questionário dividido em duas partes: a primeira parte referente a identificação dos respondentes, e a segunda parte consta de um caso de uma criança com doença terminal e três questões referentes a reaçōes sentidas pelos profissionais. (ANEXO I).

Inicialmente foi realizado um teste piloto para avaliação e reformulação do questionário.

O questionário foi enviado à chefia de enfermagem e remetido após uma semana.

Para a tabulaçáo dos dados foram utilizados os estágios do morrer segundo KUBLER-ROSS ${ }^{5}$. Na segunda questão foi utilizado o guia de comunicação com pais de WHALEY VrONG ${ }^{9}$. Também ioi utilizado uma categorizaçāo própria para as segunda e terceira questōes.

O tratamento estatístico empregado foi descritivo com distribuição de frequência absoluta e relativa.

\section{APRESENTAÇĀO E DISCUSSÃO DOS RESULTADOS}

Dos 46 questionários enviados, apenas 35 foram respondidos sendo 2 impressus incompletos. Não foram consideradas as respostas não pertinentes à pergunta.

\subsection{Características da população}

Quanto ao sexo a amostra foi constituída de 31 enfermeiros do sexo feminino e de 4 profissionais que náo se identificaram. A maioria apresenta idade situadá cistre 20 e 30 anos (85\%) e os demais entre 31 e 39 anos.

A religião predominante é a católica (60\%), sendo que 2 enfermeiros (5\%) afirmam nāo ter religiāo e 7 (20\%) nāo a identificaram.

Èm relação ao tempo de atuaçāo profissional 15 enfermeiros $(42,9 \%)$ tem até 2 anos de atividade; 5 deles $(14,2 \%)$ tem até 4 anos; do restante, $6(17,1 \%)$ tem de 5 a 10 anos de atividade e $9(25,8 \%)$ nāo identificaram. Desta forma $(57,2 \%)$ destes tem atividade profissional com duração cie até 4 anos.

\subsection{Tipo de reasóes que os profissionais esperam que a familia tenha.}

A Takiela 1 mostra a representaçāo das respostas dos enfermeiros quanto ao tipo de reaçāo que esperam da família. 
TABELA 1

DISTRIBUIC̄ÃO DAS RESPOSTAS DOS ENFERMEIROS QUANTO AS REAÇŌES QUE ESPERAM DA FAMfLIA, SÃO PAULO, 1987.

\begin{tabular}{l|c|c}
\hline REAÇŌES* & No & $\%$ \\
\hline Negação e Isolamento & 32 & 34, (í \\
Ira e Culpa & 25 & 26,60 \\
Barganha & 03 & 3,20 \\
Depressão & 22 & 23,40 \\
Aceitação & 12 & 12,76 \\
\hline TOTAL & $94^{* *}$ & 100,00 \\
\hline
\end{tabular}

* A sequência das reaçðes foi mantida de acorde com a classificação de KUBLER-ROSS 5 .

** Os enfermeiros identificam mais de uma reação; este número se refere ao número de respostas e não ao número de enfermeiros.

A partir dos dados apresentados na Tabela I observa-se que os enfermeiros identificam as reações que a família passa, não necessariamente da mesma forma apresentada por KUBLER-ROSS ${ }^{5}$, mas com maneira própria de expressāo. PerceDè-se que os enfermeiros nāo identiticam na mesma resposta todos os estágios.

A negaçāo, como reação esperada da família, aparece mais frequentemente nas respostas dos enfermeiros $(34,04 \%)$. Esta reaçāo apresenta-se descrita de várias formas, como por exemplo: "...estavam cientes do prognóstico da doença, mas persistia a esperança..." e, "...negação da realidade..."

As reaçōes decorrentes do estágio de ira e culpa, aparecem a seguir em $26,60 \%$ das respostas e foram descritas em frases como: “...transferem o sentimento de culpa para os demais", e também "... reaçōes de culpa, hostilidade e agressividade perante os médicos e funcionários".

As reaçōes inerentes ao estágio de depressāo aparecem em $23,40 \%$ das respostas e as do estágio de aceitaçāo em $12,76 \%$, e sāo apresentadas, respectivamente, da seguinte forma: "...desespero e tristeza", e, "...aos poucos a família vai se acalmando e aceitando o fato como inevitável".

$O$ estágio de barganha foi o menos identílicado pelos enfermeiros $(3,20 \%)$ sendo que uma das respostas foi descrita como: "...iccorrer à religiāo como tentativa de adiar a morte da criança, por meio de bargáinina...".

A negação é uma forma de falsear a realidade, que pode ser utilizada pela familia, diante da situaçāo de morte iminente da criança. Pode-se supor que esta reação tenha aparecido com ınaior freqüência devido a possibilidade dos familiares em utilizar diversos recursos para transmitir esta reação, seja ela verbal, direta ou indiretamente. Ob̉serva-se que os enfermeiros podem manter a situação de negaçāo por sentirem dificuldade em trazê-los para a realidade.

Já no estágio de ira, a raiva e a revolta se propagam em todas as direções e se projetam em todo o ambiente. Segundo KUBLER-ROSS ${ }^{5}$, o pessoal do hospital É alvo constante dessa raiva, pois para os tamiliares eles jamais cuidam adequa- 
damente do paciente, por mais que a equipe se esforce em fazê-lo. Há muito de inveja nesta reação, pois os familiares geralmente sentem frustados por não estarem com o paciente todo o tempo e podem se sentir impotentes em cuidar deste.

Acredita-se que o estágio de barganha, tenha sido menos identificado pelas enfermeiras pois, segundo KUBLER-ROSS ${ }^{5}$, a maior parte das barganhas são feitas com Deus e mantidas em segredo. Sendo assim, se torna mais difícil para o profissional identificar estas reaçōes.

Observa-se que as reações decorrentes do estágio de depressão, foram frequentemente descritas pelos profissionais pois segundo GAUDERER ${ }^{3}$, a maioria dos seres humanos funciona num referencial de certo e errado e nāo conseguem perceber a depressāo como algo essencialmente saudável se for vista como um ponto de reflexāo para o crescimento. Daí a necessidade do enfermeiro em tentar modificar as reaçōes dos familiares, que podem se manifestar tanto física quanto psiquicamente, animando-os. Acredita-se que nesse momento há pouca necessidade de palavras. BOEMER ${ }^{2}$ diz que apenas um toque de carinho, um afago ou um sentar-se "ao lado", é suficiente para permitir que esta familia expresse o seu pesar e assim encontre uma aceitaçāo final muito mais fácil.

Acredita-se que o estágio de aceitação dependerá de alguns fatores, como um relacionamento sincero com a equipe e também a própria evolūio da criança, onde diante do sofrimento desta, os familiares podem acreditar que a morte seria o melhor. Quando as enfermeiras identificam o estágio de aceitaçāo, parecem demonstrar que nesta fase, há um melhor relacionamento se a familia foi informada e orientada durante todo o curso da doença, como nos mostra a resposta de um dos enfermeiros: "...quando não há mentiras e há esclarecimentos de suas dúvidas, reagem de uma forma menos desesperadora, mostrando-se firmes diante do quadro clínico".

3.3. Respostas dos enfermeiros segundo a assistência que prestariam à familia.

De acordo com o seu conteúdo as respostas obtidas agrupadas como mostra a TABELA 2:

TABELA 2

DISTRIBUICẢO DAS RESPOSTAS IDOS ENFERMEIROS SEGUNDO A ASSISTENCIA QUE PRESTARIANI A FAMILIA, SAOPAULO, 1987

\begin{tabular}{|c|c|c|}
\hline Assistência que Prestariam & $\mathrm{N}^{2}$ & $\%$ \\
\hline $\begin{array}{l}\text { Utilizaşāo de formas terapêuticas } \\
\text { de comunicaçăo } \\
\text { Esclarecimentos sobre o diagnós- } \\
\text { tico, evoluçāo, prognóstico, } \\
\text { tratamento } \\
\text { Esclarecimentus sobre rotinas } \\
\text { Outros recursos }\end{array}$ & $\begin{array}{l}50 \\
29 \\
2 \\
4\end{array}$ & $\begin{array}{l}58,83 \\
34,11 \\
2,35 \\
4,71\end{array}$ \\
\hline TOTAL. & $85^{*}$ & $10(0,0)$ \\
\hline
\end{tabular}

Os enfermeiros propōe mais de um tipo de assistência; este número se referc ao número de respostas e não a) número de enfermeiros. 
Observa-se na TABELA 2, que a "utilização de formas terapêticas de comunicaçāo" aparece com maior frequência, 58,83\% como uma maneira de se prestar assistência à família; $34,11 \%$ dos enfermeiros sugerem "esclarecimentos sobre o diagnóstico, e evoluçāo, prognóstico", mostrando assim que estes estão preocupados em atender a familia emocionalmente, querendo dar um maior apoio através destes esclarecimentos. Essa afirmação se fortalece quando se observa que apenas duas respostas $(2,35 \%)$ estão relacionadas com "Esclarecimentos sobre rotinas do hospital", o que se trata de algo técnico e burocrático. Já GAUDERER ${ }^{3}$, diz que, os profissionais se deteêm menos com os problemas emocionais, afastando-se deles por se sentirem inseguros quanto à morte. E a prática tem nos mostrado que essa afirmação é verdadeira. Assim após a análise desta questão fica uma dúvida: Será que eles realmente estão mais preocupados com o lado emocional da familia, ou isto é apenas uma proposta que não é encontrada na prática?

Ao notar que a "Utilização de formas terapêtuticas de comunicação" apareceu com a maior frequência, decidiu-se usar o guia WHALEY \& WONG ${ }^{9}$ de comunicação com os pais para classificar e quantificar estas respostas. $\mathrm{O}$ resultado dessa classificação é apresentado na Tabela 3:

TABELA 3

DISTRIBUIÇĀO DAS RESPOSTAS DOS ENFERMEIROS, SEGUNDO A UTILIZAÇÃO DE FORMAS TERAPEUTICAS DE COMUNICAÇÃO WHALEY \& WONG9, COMO FORMA DE ASSISTENCIA, SÃO PAULO, 1987.

\begin{tabular}{|c|c|c|}
\hline $\begin{array}{l}\text { FORMAS TERAPÊUTICAS } \\
\text { DE COMUNICAÇÁO }\end{array}$ & No & $\%$ \\
\hline $\begin{array}{l}\text { Evitar bloqueios ou obstaculos } \\
\text { na comunicaçăo com a famnlia } \\
\text { Prover aceitaçমo } \\
\text { Ouvir } \\
\text { Estimular a famflia a falar } \\
\text { Focalizar o assunto } \\
\text { Definir o problema da famflia }\end{array}$ & $\begin{array}{r}30 \\
8 \\
4 \\
3 \\
3 \\
2\end{array}$ & $\begin{array}{r}60,00 \\
16,00 \\
8,00 \\
6,00 \\
6,00 \\
4,00\end{array}$ \\
\hline TOTAL & $50^{* *}$ & 100,00 \\
\hline
\end{tabular}

* As formas que năo apareceram foram: uso do silencio e solucionar os problemas dos familiares.

** Os enfermeiros propóe mais de uma forma teraptutica de comunicaçăo; este número é referente ao número de respostas e não ao número de enfermeiros.

Analisando os resultados desta Tabela, nota-se que a forma terapêutica de comunicaçāo mais utilizada foi "Evitar bloqueios ou obstáculos na comunicação com a família" (60\%). Talvez isto tenha ocorrido pela já citada preocupaçāo do enfermeiro com a parte emocional da familia. Fazendo uso desta forma terapêtica de comunicação, o profissional pode facilitar a assistência emocional, pois pode conseguir uma maior aceitação por parte da familia.

O segundo item citado é o de "Prover Aceitaçāo" (16\%). Através das res- 
postas, nota-se que este item está extremamente ligado ao primeiro, pois os enfermeiros citam a necessidade da existência de uma confiança entre profissionais e familia, para se prover aceitação, fazendo com que a família enfrente o problema adequadamente. BOEMER ${ }^{2}$ diz que é necessário que se esteja atento para compreender os sinais que a família deseja saber e como estāo preparados a aceitar. Os enfermeiros devem tratar a familia como pessoas capazes de sentir, pensar e agir em benefício da criança, assim seu papel se concentra em reforçar essa capacidade de solucionar os problemas da criança capacitando-a para melhor perceber as reações desta.

Pode-se agrupar os quatro próximos itens que constam na TABELA 3, que sāo: "Ouvir" ( $8 \%$ ), "Estimular a familia a falar" (6\%), "Focalizar o assunto" (6\%) e "Definir o problema" (4\%).

De acordo com BOEMER ${ }^{2}$, as famílias são capazes e necessitam discutir seus sentimentos sobre morte. Os enfermeiros devem estar preparados para manejar estes sentimentos e discutir alternativas, lembrando sempre que a morte afeta as pessoas de maneiras diferentes. WHALEY \& WONG ${ }^{9}$ afirmam que aquilo que se percebe no comportamento da familia está influenciado pelos preconceitos, percepşües e pressupostos. A família deve ser ouvida a partir de seu próprio ponto de vista, o que renı sempre é feito pelo profissional de forma adequada. Segundo GAUDERER ${ }^{3}$, o ser humano tem dificuldade em ouvir no sentido de realmente escutar. Ouve-se mas realmente não se escuta o outro, ouve-se o que ele tem a dizer, mas não o que ele quer transmitir emocionalmente.

Das formas de comunicaçāo terapêutica, nāo foram encontrados nas respostas obtidas o uso do "Silêncio" e "Solucionar os problemas da familia".

O uso do "Silêncio" é uma das técnicas mais difíceis de se aprender como afirma WHALEY \& WONG ${ }^{9}$. Talvez por esse motivo esta técnica não tenha aparecido nas respostas como também pela dificuldade em suportá-lo e pela necessidade que as pessoas tem em dar informaçōes. "Solucionar problemas da familia" talvez tenha sido omitida por ser uma dificuldade do enfermeiro em facilitar para que a familia tome decisōes no processo de soluções de problemas.

Cabe ainda comentar que não aparece nas respostas nada relacionado com o preparo da familia para o momento da morte nem para o que está experimentando após este fato. GAUDERER ${ }^{3}$ diz que existe um receio muito grande em explorar o funcionamento normal de uma pessoa, exacerbado pela falta de treinamento ou ensinamento durante os anos da faculdade. Ele diz também, que o profissional devese preparar e também à sua equipe para a morte da criança, e assim tentar preparar a família para uma possibilidade deste evento ocorrer. Para tal é necessário uma capacidade muito grande e que deve ser maior inclusive do que a de informar, educar e esclarecer. 
3.4. Respostas dos enfermeiros segundo as dificuldades sentidas na assistência à familia.

Na tabela 4 encontram-se os dados pertinentes às dificuldades sentidas pelos enfermeiros na assistência à família em situaçāo de morte iminente.

\begin{tabular}{l|c|c}
\hline DIFICULDADES & No & $\%$ \\
\hline SENTIDAS & 23 & 32,86 \\
Frente às reaçōes da famflia & 21 & 30,00 \\
Despreparo profissional & 9 & 12,86 \\
Envolvimento pessoal & 6 & 8,57 \\
Impotência & 6 & 8,57 \\
Despreparo pessoal & 5 & 7,14 \\
Rotinas & $70^{*}$ & 100,00 \\
\hline TOTAL & \\
\hline
\end{tabular}

* Os enfermeiros apresentam mais de um tipo de dificuldade na assistência à famf́lia; este número se refere ao número de respostas e năo ao número de enfermeiros.

A TABELA 4 mostra como dificuldade sentida por enfermeiros, na sua maioria, o assistir a familia a partir das "Reaçōes que esta expressa" $(32,86 \%)$.

Como já apresentado na TABELA 1, os enfermeiros conseguem identificar as reações da familia. Pode-se supor que a dificuldade sentida entāo é em como lidar com as mesmas.

Acredita-se que este fato esteja relacionado ao "Despreparo profissional", como se pode perceber na TABELA 4, onde aparece como segunda resposta mais frequente $(30 \%)$.

Um outro fator que pode estar relacionado é o "Despreparo emocional do enfermeiro". Esta relaçāo fica clara em respostas do tipo "Se a enfermeira não trabalha com o problema, nāo poderá dar conforto algum aos familiares", onde a enfermeira admite a falta de preparo para prestar assistência.

KASTENBAUM \& AISEMBERG ${ }^{4}$ afirmam que as atitudes para com a vida e a morte serão aprendidas pelos profissionais durante a sua formação em seu meio étnico e sócio-econômico.

A influência do meio profissional seria menos se estes tivessem recebido treinamento e supervisão adequada durante sua formação profissional.

Ao contrário BOEMER ${ }^{2}$ diz que o que se observa é que as escolas de saúde tendem a sugerir a preservação da vida como um sucesso do profissional e a constatação de morte próxima como um fracasso, e isso até pode contribuir para que não haja na assistência prestada um envolvimento pessoal. 
Observam-se controvérsias no que se refere ao enfermeiro deixar ou não transparecer suas emoçōes e reaçōes.

KASTENBAUM \& AISEMBERG 4 fazem citações à esse respeito: “...alguns enfermeiros preocupam-se e se envolvem com que seus pacientes estão sofrendo. Todavia, também é típico do enfermeiro acreditar que nāo deve entregarsi a seus sentimentos ao ponto de exibí-los aos outros, sendo reforçada essa atitude na sua própria formação profissional".

Percebe-se ná IABELA 4 que sentimentos de "Impotência e Despreparo pessual" aparecem numa mesma proporção de respostas $(8,57 \%)$. Supōem-se que essa impotência seja uma decorrência do próprio despreparo pessoal.

Em uma de suas publicaçōes GAUDERER ${ }^{3}$ afurma que devido a essa sensaçāo de impotência perante a morte toda cultura ou civilizaçāo desenvolveu nas suas religiōes o conceito de "eternidade". Este medo da morte e de nossa terminalidade leva o profissional de saúde a se preocupar mais com uma problemática "orgânica", que é algo palpável e mais objetivo, do que com a parte emocional, que implicaria em ter que analisar também os próprios medos, receios, inseguranças e outras emoçōes que podem ser frequentemente desconfortáveis.

Por último, aparecem ainda como dificuldades, na assistência à familia as "Rotinas e normas hospitalares" (7,14\%). Considera-se um fator impurtonte, mas questionável, uma vez que a mudança destas poderiam ser feitas por intermédio deles próprios. Seriam estas rotinas tidas como dificuldades ou simpiesmiente uma maneira do enfermeiro se esconder atrás destas para nāo enfrentar a famíriá?

Ainda assim todas essas dificuldades podem estar relacionadas ao tempo de atuaçào e a idade do enfermeiro. É esperado que o tempo de atuaçāo possa ter inlluência na "Aceitaçào da morte" pelo próprio enfermeiro. Mas acredita-se que o que possa ocorrer é uma maior segurança em saber como lidar com a morte a partir de experiências vividas. Porém, isso pode não ocorrer, como cita KUBLERROSS $^{5}$ quando descreve um caso em que ao perguntar a cada enfermeira de uma unidade hospitalar qual seria o seu papel diante de um paciente em fase terminal, a enfermeira mais velha disse achar um verdadeiro absurdo perder tempo precioso com quem nào pode mais receber ajuda.

\section{CONCLUSŌES E RECOMENDAÇŌES}

Neste trabalho foram utilizados as respostas de 35 enfermeiros, sendo eles 31 do sexo feminino e 4 não se identificaram. $85 \%$ dos enfermeiros apresentam idade entre 20 e 30 anos. A religião predominante é católica $(60 \%)$, e a maioria tem atuação profissional de até 4 anos $(57,2 \%)$.

Os enfermeiros identificam as reaçōes esperadas pela familia em situação de morte iminente da criança. De acordo com a classifica วo dos estágios da morte de 
KUBLER-ROSS ${ }^{5}$, a que apareceu em maior frequência das respostas, $(34,04 \%)$, foi a de negaçăo, em seguida, ira e culpa $(26,60 \%)$.

Em relaçāo à assistência proposta pelos enfermeiros a que esteve presente em maior frequência, $(58,83 \%)$ foi a utilização de formas terapêuticas de comunicaçăo, segundo WHALEY \& WONG ${ }^{9}$ e dentre estas formas a mais usada foi evitar bloqueios de obstáculos na comunicação com a família (60\%). Ainda apareceram como propostas de assistência, esclarecimentos sobre diagnóstico, evoluçāo, prognóstico e tratamento $(34,11 \%)$; esclarecimento de rotinas $(2,35 \%)$; outros recursos $(4,71 \%)$, que incluem manter grupos de pais e recorrer a outros profissionais.

Dentre as dificuldades encontradas pelos profissionais ao assistirem esta familia, apareceram lidar com reações que esta familia poderá apresentar, despreparo profissional, envolvimento pessoal, impotência, despreparo pessoal e rotinas sendo que a dificuldade sentida em maior frequência $(32,86 \%)$ foi lidar com as reações que a família poderá apresentar.

A partir dos resultados obtidos, dos questionamentos e das consideraçōes que os autores afirmam, sente-se a necessidade de sugerir tanto nas escolas de enfermagem quanto nas instituiçōes hospitalares de atendimento à criança, que:

- Reserve um espaço nos currículos das Escolas de Enfermagem para esclarecimentos e discussões sobre o assunto, apresentando experiências de profissionais sobre o tema;

- Inclua no plano da assistência de enfermagem à criança terminal, a assistência à família, a fim de levá-los a participar, desenvolver confiança e permitir que expressem seus sentimentos;

- Sejam utilizados pelos profissionais recursos que facilitem a expressão dos sentimentos dos familiares, como por exemplo, a utilização das técnicas de comunicação propostas por WHALEY \& WONG ${ }^{9}$;

- Haja um incentivo das Instituiçöes em formar grupos de pais, para que estes discutam a situação comum;

- Formem grupos de profissionais que lidam com a criança em fase terminal e a familia, a fím de que além de trocarem experiências, tenham um espaço para expressar seus sentimentos;

- Sejam feitas novas pesquisas para que se continue buscando outras alternativas de assistência.

HORTA, A. L. DE M.; ARAÚJO, A. P. C.; APRILE, C. M.; ECHALAR, C. M.; PAREDES, $F$. N.; CAMINADA, $S$. Children terminally aill: family reaction to assistence given and the difficulties felt by the nurse of the pediatric ward. Rev. Esc. Enf. USP, Säo Paulo, 23(2): - , Aug. 1989. 
This study reported family's reaction of the child terminally ill, identified by the pediatric nurses. It focuses on the suggested assistance to the family and on the pediatric nurses difficulties in this situation.

This study was carried out with 35 nurses working at two University Hospitals. We based the analysis on the phases of dying of KUBLER-ROSS and Guide of Communication with parents of WHALEY \& WONG, besides our own categorization.

\section{UNITERMS: Pediatric nursing. Nursing care. Terminal care.}

\section{BIBLIOGRAFIA}

1. BOEMER, M. R. A morte, o morrer e o morrendo: estudo de pacientes terminais. Ribeirăo Preto, 1985. 205 p. (Tese de Doutorado - Escola de Enfermagem de Ribeirão Preto da USP).

2. - Assistencia a pacientes terminais. Rev. Paul. Hosp., Såo Paulo, 31(1/2):33-7, jan./fev. 1983

3. GAUderer, E. C. A criança, a morte e o luto. J. Pediat. Rio de Janeiro, 62(3):82-94, mar. 1987.

4. Kastenbaum, R \& Aisenberg, R. Psicologia da morte. Sāo Paulo, Pioneira, $1983.445 p$.

5. KUBLER-ROSS, E. Sobre morte e o morrer. Sāo Paulo, Martins Fontes, 1981. 90p.

6. MANZOLLI, M. C. A morte e o morrer: aspectos psicológicos. Sāo Paulo, Sarvier, 1983. p. 91-102.

7. MARTINS, J. de S. A morte e os mortos na sociedade brasileira. São Paulo, Hucitec, 1983. 339p.

8. WILlianS, H. A. et alii. The child is dying: who helps the family? MCN, New York, 6(6):261-65, July/Aug. 1981 .

9. WHALEY, L. F. \& WONG, D. L. Essentials of pediatric nursing. Saint Louis, Mosby, 1982. $943 p$.

\section{ANEXO I}

Săo Paulo, 30 de junho de $\mathbf{8} 87$.

Prezada Enfermeira,

Nós, alunas do $4^{\circ}$ ano de graduaçāo da Escola de Enfermagem da Universidade de São Paulo, estamos realizando um trabalho com o objetivo de conhecer a percepção de enfermeiros de Unidade de Pediatria frente a situação de morte. Para atíngirmos este objetivo contamos com a sua participaçāo através do preenchimento deste questionário.

Desde já agradecemos a sua atenção e participaçāo.

Ana Paula de Campos Araújo Carla Metello Aprile Constanza Machado Echalar Fátima Neves Paredes Sirlene Caminada Ana Lucia de Moraes Horta 


\section{QUESTIONÁRIO}

IDENTIFICAÇĀo

IDADE: SEXO:

TEMPO DE ATUAÇĀO PROFISSIONAL EM UNIDADE PEDIÁTRICA:

RELIGIĀO:

\section{HISTÓRIA}

Uma criança de 7 anos foi hospitalizada com o diagnóstico de Leucemia Linfóide Aguda e submetida a um esquema de quimioterapia, apresentando náuseas, vốmitos, emagrecimento acentuado e alopécja como efeitos colaterais.

A famnlia conhecia o diagnóstico, porém evitava qualquer tipo de comentário. A certeza de que a criança fosse sair curada, era frequentemente verbalizada pelos pais e era acentuada após cada sinal de melhora, como por exemplo: edema causado pela corticoterapia era percebido como ganho de peso e melhora do quadro: Com o decorrer do tratamento houve melhora clínica quanto a doença de base, porém a criança passou a apresentar infecçāo pulmonar grave, e seu prognóstico no momento é considerado fechado. A familia acabou de ser comunicada.

\section{PERguntas}

1. Que tipo de reaçôes desta famflia você espera?

2. Qual a assisténcia que você prestaria à esta famnia desde o início da internação?

3. Para você quais as dificuldades sentidas na assistência à famflia em situação de morte iminente?

Recebijo para publicaçāo em 08/03/88. 